Journal of Management and Economics for Iberoamerica

Artigo de revisão

\title{
Empreendedorismo social e inovação social: uma análise bibliométrica
}

Emanuel Campigotto-Sandri*

Doutorando, Programa de Pós-Graduação em Administração, Universidade Federal do Paraná, Curitiba, Brasil. emanuel.sandri@hotmail.com

Itamir Caciatori-Junior

Doutorando, Programa de Pós-Graduação em Administração, Universidade Federal do Paraná, Curitiba, Brasil. itamircj@gmail.com

Pedro Chapaval-Pimentel

Doutorando, Programa de Pós-Graduação em Administração, Universidade Federal do Paraná, Curitiba, Brasil. professorchapaval@gmail.com

Rivanda Meira-Teixeira

Professora, Programa de Pós-Graduação em Administração, Universidade Federal do Paraná, Curitiba, Brasil. rivandateixeira@gmail.com

\section{Resumo}

Apesar da existência de revisões sistemáticas e estudos bibliométricos que tratam do empreendedorismo social e da inovação social de forma isolada, estudos que abordam esses dois temas de forma conjunta ainda são escassos. 0 objetivo deste estudo é mapear a produção acadêmica sobre empreendedorismo social e inovação social por meio da técnica bibliométrica como método de pesquisa. Foram avaliados trabalhos indexados na base de dados Scopus por meio da análise de citaç̃os, co-citações e análise textual. Os resultados apontam para o crescimento no interesse científico sobre os dois temas, quando analisados de forma conjunta. Entretanto, a ênfase desses estudos está no empreendedorismo social sendo que a inovação social aparece como elemento secundário, característica ou resultado do processo empreendedor.

Palavras-chave: empreendedorismo social; inovação social; bibliometria.

\section{Emprendimiento social e innovación social: un análisis bibliométrico}

\section{Resumen}

A pesar de que existen revisiones sistemáticas o estudios bibliográficos que abordan el emprendimiento social y la innovación social de forma aislada, hay pocos estudios que abordan estos dos temas en conjunto. El objetivo de este estudio fue mapear una producción académica sobre emprendimiento social e innovación social con una técnica bibliométrica como método de investigación. Se utilizó la base de datos Scopus para el análisis de citas, co-citas y el análisis textual. Los resultados apuntan al crecimiento en el interés científico de analizar estos dos temas en conjunto; sin embargo, se observa que el énfasis de estos estudios está en el emprendimiento social y que la innovación social aparece como un aspecto secundario, característica o resultado del proceso emprendedor.

Palabras clave: emprendimiento social; innovación social; bibliometría.

\section{Social entrepreneurship and social innovation: A bibliometric analysis}

\section{Abstract}

Despite the existence of systematic reviews or bibliographic studies on social entrepreneurship and social innovation in isolation, few studies address these two issues together. The objective of this study was to map an academic production on social entrepreneurship and social innovation with a bibliometric technique as a research method. The Scopus database was used for the analysis of citations, co-citations, and textual analysis. Results point to the growth in scientific interest in analyzing these two issues together. However, it is observed that the emphasis of these studies is on social entrepreneurship and that social innovation appears as a secondary aspect, characteristic or result of the entrepreneurial process.

Keywords: social entrepreneurship; social innovation; bibliometrics.

* Autor para dirigir correspondência.

Classificações JEL: M1; M19; M10.

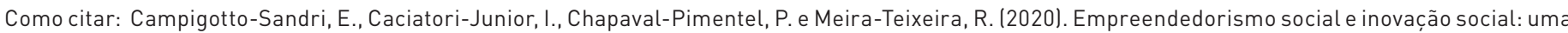
análise bibliométrica. Estudios Gerenciales, 36(157), 511-524. https://doi.org/10.18046/j.estger.2020.157.3886

DOI: https://doi.org/10.18046/j.estger.2020.157.3886

Recebido: 7-fev-2020

Aceito: 23 -set-2020

Publicado: $30-$ dez-2020 


\section{Introdução}

Empreendedorismo social e inovação social são conceitos que vêm recebendo cada vez mais atenção tanto da sociedade como da academia. Durán-Sánchez, Peris-Ortiz, Álvarez-García e del Río (2018) explicam que a maior parte dos trabalhos exploram a existência de oportunidades para a inovação social no campo do empreendedorismo social, mas destacam a escassez de trabalhos revisionais que avaliem as duas temáticas de forma conjunta.

Embora as duas temáticas possuam definições diferentes e não possam ser entendidas como sinônimos ou condicionantes uma da outra (Phills, Deiglmeier e Miller, 2008), há uma aproximação entre o empreendedorismo social e a inovação social. Ambos os fenômenos dizem respeito à promoção de melhorias para a sociedade e à solução de problemas sociais. Além disso, destaca-se a complementaridade existente entre diferentes empresas sociais e processos de inovação social, uma vez que esta serve de estratégia para que as atividades daquelas alcancem maior impacto social e gere maior valor social (Blanco-Ariza, Messino-Soza, Vázquez-García e Melamed-Varela, 2019; Mulyaningsih, Yudoko e Rudito, 2016).

Ainda que diversos autores apontem o empreendedorismo social como um campo de pesquisa em estágio inicial, percebe-se que esse campo integra o cenário empreendedor de forma crescente (Macke, Sarate, Domeneghini e da Silva, 2018; Sassmannshausen e Volkmann, 2013). Conforme Weerawardena e Sullivan Mort (2006) explicam, o empreendedorismo social pode ser definido como um construto multidimensional cujo principal resultado é a criação de valor social. Esse modelo de empreendedorismo se dá em função de atitudes comportamentais (inovação, proatividade e gestão de riscos) e está sujeito a interações com um ambiente dinâmico, na busca de um negócio sustentável e no cumprimento de uma missão social.

Abordagens mais recentes na literatura sobre empreendedorismo, explicam que a motivação do empreendedor social está voltada ao lucro, seja como fim ou como meio do processo empreendedor (Phillips, Lee, Ghobadian, O'Regan e James, 2015). No entanto, a visão de Dacin, Dacin e Matear (2010) é a de que o empreendedorismo social contribui para um campo interdisciplinar ao contestar a tradicional visão econômica de desenvolvimento - i.e. lucro -, transcendendo os estudos sobre o indivíduo, os movimentos sociais e as organizações sem fins lucrativos.

A inovação social, por sua vez, pode ser entendida como um produto ou processo, novo ou aprimorado lou uma combinação de ambos), visando melhorar o bemestar de indivíduos ou comunidades (Mulgan, Joseph e Norman, 2013; Organização para a Cooperação e Desenvolvimento Econômico - OECD/Eurostat, 2018). No que concerne aos estudos sobre inovação social, Adams e Hess (2010) apontam o crescimento das discussões nos campos político e acadêmico. A inovação social, nesse sentido, não se limita a aspectos relacionados à alta tecnologia ou exclusivamente ao crescimento econômico, mas enfatiza a promoção de soluções inovadoras para problemas sociais. 0 desenvolvimento das inovações sociais, portanto, possui potencial para alterar a estrutura de sistemas de inovação e da sociedade (Adams e Hess, 2010).

A inovação social passou a ser entendida não apenas como força motriz e princípio estruturante de muitas Organizações da Sociedade Civil, mas como uma ponte entre iniciativas coletivas e a transformação das relações sociais de diversas comunidades (Moulaert, 2016). Focadas principalmente na criação de valor social e em soluções para problemas da sociedade, elas se tornaram elementos importantes para a resolução de diversos problemas, como a pobreza e a fome, que atingem especialmente países em desenvolvimento (Nicholls, Simon, Gabriel e Whelan, 2015).

Levantamentos bibliográficos recentes demonstram a existência de trabalhos que articulam os temas "inovação" e "empreendedorismo social" de forma conjunta (Silveira e Zilber, 2017). Este é o caso de trabalhos que fazem revisões sistemáticas (Mulyaningsih et al., 2016; Phillips, Lee, Ghobadian, O’Regan e James, 2015) ou que abordam os temas de forma periférica utilizando outras palavras-chave em conjunto (Farinha, Sebastião, Sampaio e Lopes, 2020). Apesar da existência de estudos bibliométricos que tratam do empreendedorismo social lCarmona, Martens, Leão, Nassif, e Freitas 2018; Dionisio, 2019; Hota, Subramanian e Narayanamurthy, 2019; Kraus, Filser, O'Dwyer e Shaw, 2014; Rey-Martí, Ribeiro-Soriano e Palacios-Marqués, 2016) e da inovação social (Ayob, Teasdale e Fagan, 2016; Blanco-Ariza et al., 2019; Foroudi, Akarsu, Marvi e Balakrishnan, 2020; Gaitán-Ângulo, Díaz, Viloria, Lis-Gutiérrez e RodríguezGarnica, 2018; González e Lutsak-Yaroslava, 2017; Van der Have e Rubalcaba, 2016) de forma isolada, não foram encontrados trabalhos que façam a utilização de técnicas estatísticas para avaliar exclusivamente os temas do empreendedorismo social e da inovação social em conjunto (Farinha et al., 2020; Mulyaningsih et al., 2016; Phillips et al., 2015).

Diante da relevância dessas temáticas tratadas em conjunto, e da necessidade de análises objetivas, definiu-se a seguinte questão de pesquisa: como se caracteriza a produção científica voltada para os campos de empreendedorismo social e inovação social de forma conjunta?

Para responder à pergunta de pesquisa, foram aplicadas técnicas de análises bibliométricas como estratégia metodológica. Foram realizadas análise de citações, co-citações e análise textual, em artigos indexados na plataforma Scopus, que tratam do empreendedorismo social e da inovação social de forma conjunta.

0 estudo é composto por cinco seções. Após esta introdução, tecem-se considerações sobre empreendedorismo social e inovação social, e são apresentados estudos revisionais que tratam de ambos os temas. 
$\mathrm{Na}$ terceira seção são descritos os procedimentos metodológicos adotados, seguidos, pelos resultados e sua discussão. Por fim, na quinta seção são apresentadas as considerações finais, bem como sugestões para pesquisas futuras.

\section{Fundamentação teórica}

\subsection{Empreendedorismo social}

0 empreendedorismo como base teórica teve suas origens fundamentadas em disciplinas estabelecidas como a economia, a psicologia e a sociologia, fazendo com que os modelos teóricos contemporâneos a respeito do campo sejam entendidos como fragmentados (Landström, Harirchi, e Åström, 2012; Moroz e Hindle, 2012). Entretanto, é possível verificar que a essência do fenômeno reside na necessária relação entre indivíduos e oportunidades, pois a existência de oportunidades que possam gerar resultados financeiros e de indivíduos empreendedores, são aspectos indispensáveis para a compreensão do empreendedorismo (Moroz e Hindle, 2012)

0 estudo do fenômeno envolve, portanto, a avaliação do processo em que indivíduos descobrem, avaliam e exploram oportunidades lucrativas resultando no desenvolvimento de bens e serviços (Shane e Venkataraman, 2000). 0 processo empreendedor envolve, além disso, a avaliação da criação de valor para as partes envolvidas e interessadas em novos modelos de negócios e/ou na otimização de modelos de negócios já existentes. 0 empreendedorismo diz respeito, portanto, a processos e a resultados. Por fim, o aspecto temporal é relevante, pois oportunidades não duram para sempre e a receptividade do mercado pode variar em função do momento e do contexto em que o empreendedor decidiu por explorá-las (Moroz e Hindle, 2012).

Atualmente com o uso abusivo de recursos naturais, o aumento da miséria e da fome em regiões pobres do planeta e o aumento das desigualdades sociais, têm movido debates políticos e pesquisas científicas no mundo todo na busca de soluções (Gaiotto, 2016). Nesse cenário, diversos pesquisadores apontam para o empreendedorismo como uma solução factível para, ao menos, amenizar esses problemas e direcionar a sociedade para um futuro mais sustentável (Hall, Daneke e Lenox, 2010). Diversas atividades passaram a ser atribuídas ao campo, e vêm contribuindo para a consolidação do empreendedorismo social (Gaiotto, 2016). Elementos como a economia solidária, a autogestão, a bricolagem e a inclusão social vêm sendo agregadas às discussões, e acabam por reforçar sua importância em meio às demandas sociais contemporâneas.

É importante delimitar algumas diferenças entre o empreendedorismo social e o empreendedorismo tradicional. Enquanto este tem suas atividades focadas no setor privado e o principal objetivo é maximizar o lucro, aquele trabalha voltado para a resolução de problemáticas sociais com ênfase na geração de soluções e na responsabilidade das ações de organizações (Johnson e Gilles, 2003; Phillips et al., 2015). Não é possível, contudo, ignorar a identificação e exploração de oportunidades, pois diversos empreendimentos sociais são influenciados por empreendedores que já desenvolveram projetos nas suas áreas de atuação, mas aproveitam suas redes de relacionamento para adquirir recursos e informações que possam levar à exploração de oportunidades (Onozato e Teixeira, 2010).

Para além da busca por lucro e crescimento econômico, o empreendedor social é inspirado em suas convicções pessoais na identificação e exploração de oportunidades que não se limitem a tratamentos temporários para problemas sociais (Cohen e Winn, 2007). O empreendedorismo social emerge como alternativa para a resolução de tais demandas, a partir de iniciativas que prezam pela inclusão social e valorização de pessoas, e atividades negligenciadas pelo mercado ou pelo Estado (Gaiotto, 2016).

\subsection{Inovação social}

Inovação pode ser entendida tanto como um processo, quanto como os resultados de determinado processo. O Manual de Oslo, documento essencial para avaliar processos relativos a inovações, define a palavra como um produto ou processo novo ou aprimorado (ou uma combinação de ambos) que difere significativamente de produtos ou processos anteriores, e que foi disponibilizado para usuários em potencial (produto) ou trazido para uso por determinado grupo de pessoas (processo) (OECD/Eurostat, 2018).

Ainda que a inovação social partilhe de vários atributos com a inovação tradicional, por serem novas maneiras de atenderem diversos objetivos e necessidades, a principal diferença está na intencionalidade; a inovação social visa criar e desenvolver valor social, não apenas econômico (Mulgan, 2006). Murray, Caulier-Grice e Mulgan (2010) explicam que inovações tradicionais e sociais são diferentes, estas dizem respeito a resultados e a relacionamentos desenvolvidos em prol de cooperação e colaboração, não em competição como aquelas. Desse modo, as métricas do processo, modelos e métodos utilizados para inovações tradicionais, nem sempre podem ser diretamente aplicadas em processos e produtos de economia social.

As inovações tradicionais buscam, em seus objetivos, a vantagem competitiva e a geração de lucros para seus investidores por meio de produtos, modelos comerciais ou serviços, enquanto as inovações sociais focam no resultado final do que é fornecido aos cidadãos, usuários finais e à sociedade (Dawson e Daniel, 2010; Van Der Have e Rubancaba, 2016). Pode-se dizer que as inovações sociais possuem como desafios as mudanças de atitudes, comportamentos ou percepções de um grupo de pessoas que buscam de forma conjunta, e que levam a novas e melhores formas de colaboração dentro e fora do grupo e da sociedade. 
Para Farfus e Rocha (2007), que apresentam a inovação em seu caráter social, o conceito reveste-se de qualidade cidadã e transcende o sentido meramente de valor econômico, implantando-se um objetivo social como força motivadora de mudanças. Essa maior amplitude e relevância social, direcionam a resolução de problemas como a pobreza e a ausência de cidadania. Assim, é possível definir inovações sociais pelos seus objetivos (sociais) de melhorar o bem-estar de indivíduos ou comunidades (Mulganet al., 2013; OECD/ Eurostat, 2018).

\subsection{Estudos sobre empreendedorismo social e inovação social}

A existência de estudos bibliométricos contribui significativamente para a compreensão, estudo e prática de empreendedorismo social (Carmona et al., 2018; Dionisio, 2019; Hota et al., 2019; Kraus et al., 2014; ReyMartí et al., 2016) e inovação social (Ayob et al., 2016; Blanco-Ariza et al., 2019; Foroudi et al., 2020; GaitánÂngulo, Díaz, Viloria, Lis-Gutiérrez e Rodríguez-Garnica, 2018; González e Lutsak-Yaroslava, 2017; Van der Have e Rubalcaba, 2016). Destaca-se, contudo, que a maior parte desses estudos foi realizada abordando cada um dos temas separadamente. Dessa maneira, a seguir, são apresentadas pesquisas bibliométricas que tratam do empreendedorismo social, inovação social, e revisões sistemáticas com os dois temas simultaneamente (Mulyaningsih et al., 2016; Phillips et al., 2015) ou que utilizam diversas outras palavras-chave em conjunto (Farinha et al., 2020).

0 artigo revisional sobre empreendedorismo social mais referenciado na base da Scopus (Rey-Martí et al., 2016) tem como objetivo orientar novos pesquisadores no campo do empreendedorismo social, para que conheçam quais periódicos e autores consultar ao estudar esse fenômeno. Por meio de uma análise bibliométrica de 2.922 trabalhos científicos publicados entre 2003 e 2015, os autores buscaram contribuir no mapeamento do campo do empreendedorismo social com as seguintes informações: i) a língua presente na maioria dos trabalhos publicados sobre empreendedorismo social é o Inglês; ii) a área que mais publicou sobre o tema é a Business Economics; iii) o periódico com mais publicações sobre o assunto é o Journal of Business Venturing, e; iv) o principal autor sobre empreendedorismo social, no momento em que a pesquisa foi realizada, era Alistair Anderson (ReyMartí et al., 2016).

Buscando avaliar a literatura que trata o empreendedorismo social, Carmona et al. (2018) realizaram um estudo bibliométrico que combina as técnicas de análises de citações e co-citações com análise fatorial, identificando os principais temas de pesquisa, o conhecimento acumulado e as tendências futuras sobre o empreendedorismo social. Ao avaliar 296 artigos da base de dados Scopus, evidenciou-se a dificuldade em definir o fenômeno "empreendedorismo social", as funções e motivações do empreendedor social, suas características e competências. Além disso, foram identificados seis fatores presentes dentro dos campos de estudo: al empreendedorismo, social informal e/ ou irregular; b) empreendedor e empreendimento sociais; c) contexto e campo das empresas sociais e o empreendedorismo social; d) empreendimentos sociais autossustentáveis; el motivação social, e; f) empreendedorismo social e construções de narrativas (Carmona et al., 2018).

Dionisio (2019) realizou uma análise bibliométrica em 154 trabalhos científicos publicados no periódico Social Enterprise Journal, entre as edições publicadas nos anos de 2005 e 2017. Ao mapear o campo da pesquisa, o autor demonstrou quatro categorias sobre o estado da arte do campo do empreendedorismo social: al categoria indivíduo: apresenta as características dos empreendedores sociais, suas motivações, e como avaliam oportunidades de negócios; b) categoria da organização: concentra-se nos artigos que tratam como as empresas sociais desenvolvem seus papéis como organização, e suas estratégias para manter o negócio; cl categoria processo: trabalhos que estudaram o desenvolvimento institucional, profissio-nalização da força de trabalho e métodos de medição do empreendedorismo social, e; d) categoria ambiente: interação do campo junto a outros atores, governo, comunidade e negócios relacionados ao empreendedorismo social (Dionisio, 2019).

Contribuindo para a literatura do empreendedorismo social, o estudo de Kraus e colegas (2014) identificou os principais tópicos de pesquisa sobre o tema, além dos artigos e autores mais influentes. Esse trabalho ainda discute o conceito de empreendedorismo social, definições alternativas, as fontes de empreendedorismo social e as características dos empreendedores sociais. Para alcançar isso, foram utilizadas técnicas bibliométricas e de cluster para analisar 129 artigos, identificados nas bases Emerald, EBSCO, ProQuest, ScienceDirect e Google Scholar. Como resultado, o trabalho apresentou os 20 principais artigos científicos utilizados por pesquisadores que estudam o fenômeno empreendedorismo social.

A revisão bibliométrica dos autores Hota et al. (2019) realizada na base de dados Web of Science, contando com 1.296 artigos e 74.237 referências citadas, contou com análises de citação, co-citação e as redes de autores dentro do campo do empreendedorismo social. 0 trabalho trouxe como contribuição para o campo: al identificar as principais contribuições acadêmicas no campo e as ligações entre elas; b) traçar a evolução do campo ao longo do tempo, cl analisar o campo do empreendedorismo social, e; d) explorar o papel da ética no empreendedorismo social, onde os autores compreendem que esse fator deva ser considerado ao estudar o tema.

Como ocorre no campo do empreendedorismo social, a inovação social também é contemplada com estudos bibliométricos (Ayob et al., 2016; Blanco-Ariza et al., 2019; Foroudi et al., 2020; Gaitán-Ângulo, Díaz, Viloria, Lis-Gutiérrez e Rodríguez-Garnica, 2018; González e Lutsak-Yaroslava, 2017; Van der Have e Rubalcaba, 2016) que buscaram mapear essa área de pesquisa. Dessa 
maneira, destacam-se, a seguir, pesquisas que tratam sobre inovação social.

Ayob et al. (2016), em sua revisão bibliométrica, identificaram os principais elementos que a literatura utiliza para conceituar a inovação social, sendo: a) novas formas de relações sociais que levam à inovação; b) a inovação leva a uma reestruturação das relações sociais e/ou de poder; c) a inovação leva a um valor social utilitário; d) novas formas de relações sociais levam à inovação que resulta na reestruturação das relações de poder, e; el novas formas de relações sociais levam à inovação, que cria valor social utilitário. Esses resultados foram obtidos após analisar todos os trabalhos científicos entre os anos de 1989 e 2013, contidos na base de dados Web of Science, que tratassem de inovação social.

Já o estudo bibliométrico nas bases de dados Scopus e Web of Science, realizado por Blanco-Ariza et al. (2019), buscou levantar a literatura acadêmica que apresenta os conceitos de inovação social e organizações sem fins lucrativos, publicada entre os anos de 2014 e 2015. Os autores identificaram que esses campos são complementares e constituem uma oportunidade para a geração de novas pesquisas em países onde essas pesquisas ainda não estão desenvolvidas (Blanco-Ariza et al., 2019).

0 estudo bibliométrico mais recente identificado na base de dados Scopus (Foroudi et al., 2020), além de identificar os artigos sobre inovação social mais relevantes, analisa mais de 370 estudos e 2.941 citações sobre o tema entre os anos de 2014 e 2018, e propõe um modelo para a conceituação de inovação social. 0 trabalho de Foroudi et al. (2020), utilizou métodos de escala multidimensional e análise de cluster hierárquico para a análise dos grupos que compuseram cada temática abordada no modelo desenvolvido.

Gaitán-Angulo et al. (2018) analisaram os artigos acadêmicos que trataram os estudos de inovação social e complexidade de forma conjunta entre os anos de 2007 e 2017. Para isso, os autores analisaram as bases de dados Scopus e Dialnet e identificaram que os autores que mais estudam os temas são Westley e Bishop, além de apresentarem os autores Bousquet e Hajjam como os principais pesquisadores com redes de relacionamento dentro do campo da pesquisa. Também é demonstrado que as palavras-chaves mais utilizadas em estudos dessa natureza são: mudanças, complexidade, impacto, redes sociais, design, prática e teoria (Gaitán-Angulo et al., 2018).

González e Lutsak-Yaroslava (2017) também trabalhou dois temas de forma conjunta em seu artigo bibliométrico: o desenvolvimento local e a inovação social. Com o objetivo de explicar como é produzida a inovação social e como ela contribui para o desenvolvimento territorial, a autora identificou os principais trabalhos que abordassem essas duas temáticas contando com os documentos publicados e anexados nas bases de dados Scopus e Web of Science. Como resultado, a pesquisa apresenta que o campo está em processo de crescente expansão, transformação e consolidação, tanto de forma prática quanto teórica.

0 trabalho de Van der Have e Rubalcaba (2016) traça - conteúdo, o escopo e o histórico da pesquisa sobre inovação social em todos os campos do conhecimento, aplicando análises bibliométricas e de rede para explorar a relevância específica para o campo da inovação. Para isso foram analisadas 172 publicações indexadas à base de dados Web of Science. Dentre os resultados, os autores identificaram que é possível analisar que o campo de inovação social está agrupado em quatro grupos de pesquisa: 1) psicologia comunitária; 2) pesquisas que envolvem criatividade; 3 ) desafios sociais e sociedade e; 4) desenvolvimento local.

Chalmers (2013) apresenta em seu texto revisional as produções acadêmicas que tratam sobre inovação social. 0 autor explica que esse tipo de inovação se concentra no desenvolvimento de valor social e cultural do sistema social nos quais estão inseridos. Assim, o autor explica que estudos que tratam dessa temática geram oportunidades para realizar inovações que podem solucionar diversos problemas sociais, além da possibilidade de propor modelos de negócios rentáveis por meio da mudança e transformação em todo o sistema social.

Ainda que os estudos sobre os temas de empreendedorismo social e inovação antes apresentados, não contemplem as duas temáticas de forma conjunta, alguns trabalhos (Farinha et al., 2020; Mulyaningsih et al., 2016; Phillips et al., 2015) estudaram esses dois fenômenos e suas relações. Phillips et al. (2015) utilizou trabalhos indexados na base de dados Scopus para realizar uma revisão da literatura com o objetivo de preencher essa lacuna de pesquisa, configurada pela falta de estudos que tratam os dois temas em conjunto. Os autores apresentam uma estrutura teórica robusta, mas flexível o suficiente para acomodar os conceitos e seu desenvolvimento compartilhado e sistemático. Os 122 artigos avaliados no trabalho contemplavam publica-ções entre 1987 e 2012, que forneceram informaçõescoletivas e insights sobre pesquisas que vinculam "inovação social" ao "empreendedorismo social", demonstrando crescente interesse na área ao longo da última década. Além disso, o trabalho também contempla o crescente interesse no papel das redes sociais, e a crescente necessidade dos pesquisadores de entender o tipo de rede necessária para uma inovação bemsucedida. 0 estudo de Phillips et al. (2015) ainda revelou que o empreendedorismo social e a inovação social compartilham sobreposições comuns, especialmente no processo de identificação de oportunidades e solução de problemas para necessidades sociais não atendidas.

No ano seguinte, Mulyaningsih et al. (2016) conduziram uma abordagem qualitativa ao realizar uma revisão sistemática e discutir o processo da inovação social dentro de empresas sociais, baseando-se em três fundamentos teóricos: empreendedorismo social, 
inovação social e gestão do conhecimento. Dentre as contribuições identificadas no estudo, os autores apontam que empresas sociais que buscam na inovação social estratégias para alcançar o impacto social, geram valor social por meio da comercialização de bens e serviços.

A fim de avaliar a literatura que trata das relações entre "empreendedorismo social" e "inovação social", Farinha et al. (2020) realizaram um estudo bibliométrico analisando as co-citações e a evolução da estrutura conceitual da inovação social em organizações sem fins lucrativos. Foram analisados 2.695 documentos científicos identificados na base de dados Web of Science, entre os anos de 1970 e 2019, e mapeado o estado da arte dos temas sobre "empreendedorismo social" e "inovação social" dentro das organizações sem fins lucrativos. Os autores ainda identificaram que, entre os anos de 2016 e 2019, houve uma maior concentração de estudos próximos à temática de inovação e de trabalhos científicos que abordaram as metodologias de estudo de caso demonstrando novas perspectivas quanto às pesquisas aplicadas nesta área. Destaca-se, contudo, que embora o trabalho de Farinha et al. (2020, p. 82) apresente-se como um estudo sobre inovação social e empreendedorismo social, as palavras-chave utilizadas pelos autores foram amplas - e.g. "innovation in nonprofit", "nonprofit innovation", "entrepreneurship in nonprofit" - e não se restringiram aos fenômenos em questão.

A partir desta revisão, aspectos a serem estudados nesses campos de forma associada vem à tona: como se dá a evolução do campo da pesquisa sobre empreendedorismo social e da inovação social em conjunto? Quais temas estão sendo estudados sobre essas duas áreas? Quem está pesquisando esses temas simultaneamente? Quais são os artigos-chave que influenciam o campo?

Assim, visando uma avaliação da contribuição acadêmica dos estudos que abordam as temáticas de empreendedorismo social e que contemplem a inovação social, apresenta-se a metodologia na seção seguinte.

\section{Metodologia}

A escolha da análise bibliométrica se deu em função da possibilidade de situar o estado e a evolução de determinados campos de estudo (Gutiérrez-Salcedo, Martínez, Moral-Munoz, Herrera-Viedma e Cobo, 2018). As técnicas bibliométricas são úteis porque buscam aprimorar a documentação, as informações e as comunicações científicas, por meio da análise quantitativa de conjuntos de trabalhos acadêmicos (Osareh, 1996).

Uma das formas de se obter essas informações é por meio da rastreabilidade das citações e do mapeamento das colaborações entre pesquisadores de acordo com os tópicos de pesquisa mais importantes de cada campo (Zupic e Čater, 2015). Assim, em relação às técnicas bibliométricas disponíveis, Gutiérrez-Salcedo et al. (2018) dividem-nas em "análise de desempenho" e "mapeamento da ciência". Enquanto a primeira busca avaliar o impacto das citações utilizando indicadores quantitativos, o mapeamento da ciência demonstra a estrutura conceitual, social ou intelectual do campo de pesquisa.

Os indicadores mais comumente utilizados para a aplicação dessas técnicas são os autores, os periódicos, as palavras-chave e as referências utilizadas para o desenvolvimento dos trabalhos analisados. A Tabela 1 apresenta os três métodos empregados para as análises deste trabalho, que foram definidos com base nas descrições de Zupic e Čater (2015), e na viabilidade e limitações apresentadas por Grácio (2016) e Hjørland (2013).

Tabela 1. Resumo dos métodos bibliométricos

\begin{tabular}{ll}
\hline Método & Descrição \\
\hline Citação & $\begin{array}{l}\text { Estima a influência de documentos, autores ou } \\
\text { periódicos por meio de quantidade de citações }\end{array}$ \\
Cocitação & $\begin{array}{l}\text { Associa documentos, autores ou periódicos com } \\
\text { base nas vezes em que são citados nos mesmos } \\
\text { trabalhos }\end{array}$ \\
Análise de texto & $\begin{array}{l}\text { Associa palavras com base em títulos, resumos ou } \\
\text { lista de palavras-chave }\end{array}$
\end{tabular}

Fonte: adaptado de Zupic e Čater (2015).

Assim, para além das possíveis técnicas bibliométricas, Zupic e Čater (2015) propõem cinco etapas para a execução de levantamentos bibliométricos, conforme apresentado na Tabela 2. A primeira etapa (Projeto de Pesquisal envolveu a definição da pergunta de pesquisa - Como se caracteriza a produção científica voltada para os campos de empreendedorismo social e inovação social de forma conjunta? - e do método bibliométrico como sendo o mais adequado para respondê-la.

Tabela 2. Etapas da pesquisa bibliométrica

\begin{tabular}{|c|c|}
\hline Etapa & Atividades \\
\hline \multirow[t]{2}{*}{ Projeto de pesquisa } & Definição da pergunta de pesquisa \\
\hline & $\begin{array}{l}\text { Escolha do método bibliográfico mais } \\
\text { adequado para a pergunta de pesquisa }\end{array}$ \\
\hline \multirow[t]{4}{*}{$\begin{array}{l}\text { Compilação dos dados } \\
\text { bibliométricos }\end{array}$} & $\begin{array}{l}\text { Definição das palavras-chave para busca (cf. } \\
\text { Figura 1) }\end{array}$ \\
\hline & $\begin{array}{l}\text { Levantamento dos arquivos nas bases de } \\
\text { dados }\end{array}$ \\
\hline & $\begin{array}{l}\text { Construção e agrupamento dos arquivos com } \\
\text { referências obtidas da base Scopus }\end{array}$ \\
\hline & $\begin{array}{l}\text { Filtragem e exportação dos dados } \\
\text { bibliográficos utilizando o pacote Bibliometrix } \\
\text { do software estatístico R }\end{array}$ \\
\hline \multirow[t]{2}{*}{ Análise } & $\begin{array}{l}\text { Geração dos resultados no pacote } \\
\text { Bibliometrix (R) }\end{array}$ \\
\hline & Seleção das informações para publicação \\
\hline \multirow[t]{2}{*}{ Visualização } & $\begin{array}{l}\text { Construção de tabelas e gráficos com dados } \\
\text { obtidos do Bibliometrix (R) }\end{array}$ \\
\hline & $\begin{array}{l}\text { Seleccão do software para visualização dos } \\
\text { resultados no software VOSviewer }\end{array}$ \\
\hline $\begin{array}{l}\text { Interpretação dos } \\
\text { resultados }\end{array}$ & \\
\hline
\end{tabular}

Fonte: adaptado de Zupic e Čater (2015). 
A segunda etapa (Compilação dos dados bibliométricos), descrita na Figura 1, ocorreu com a definição das palavras-chave ("social entrepreneu*" AND "social innovat*") que foram utilizadas para as buscas na base de dados Scopus. Esta base de dados foi selecionada pela capacidade de processamento de buscas de estudos acadêmicos publicados em outras bases de dados que também estão a ela indexados. A escolha também se deu pela possibilidade de coletar diversas informações como autores, ano de publicação dos trabalhos, resumos, palavras-chaves, periódicos em que foram publicados, citações e co-citações. Além de fornecer informações substanciais sobre o banco de dados, a Scopus inclui o número de registros e a lista de títulos indexados, também fornecendo recursos para navegação, pesquisas, classificações e o registro das buscas, bem como viabiliza a exportação para os softwares de gerenciamento de citações VOSviewer e Bibliometrix (Durán-Sánchez et al., 2018; Meho e Yang, 2006).

A consulta da base de dados foi realizada no dia 08 de julho de 2019 e o fluxo das atividades empregadas na segunda etapa, relativa à compilação dos dados bibliométricos, está descrito na Figura 1. A definição das palavras-chaves a serem utilizadas foi feita a partir de pesquisas realizadas em quatro fases e que possibilitaram a análise de 157 trabalhos publicados. Em primeiro lugar, foram buscadas as palavras-chave individualmente, que geraram o total de 1.542 publicações cuja temática envolvesse "social entrepreneu*", e 1.278 sobre "social innovat*". A busca pelos termos individuais se deu para identificar, inicialmente, a viabilidade de pesquisas quantitativas nos campos de estudo em questão.

Uma vez verificada a viabilidade de análises quantitativas, partiu-se para um refinamento das buscas. Como o objetivo do trabalho é compreender como as duas áreas são trabalhadas em conjunto optou-se pela utilização do operador Booleano AND e pela linha de busca ("social entrepreneu*" AND "social innovat*"). A tentativa em questão demonstrou que uma análise quantitativa seria viável, pois foram encontrados 255 trabalhos. Em seguida, foram aplicados filtros para selecionar publicações que fossem obrigatoriamente classificadas como artigo (Article) ou revisão (Review). Essa decisão foi tomada com o objetivo de excluir trabalhos que não tivessem como condição para a publicação, pois a obrigatoriedade de passar por peerreview para sua publicação reflete, ao menos em tese, em um maior rigor metodológico, teórico e analítico nas publicações. Assim, foram ignorados trabalhos em desenvolvimento (Conference Paper e Working Paper), editoriais, notas, livros e capítulos de livros etc.

Assim, além dos dados básicos dos 157 artigos e revisões (título, autor, palavras-chave), foram capturadas as referências bibliográficas dos trabalhos. Essas informações constituíram a etapa de acoplamento bibliográfico e análise de impacto dos artigos utilizados como referência.
A terceira etapa (Análise, conforme Tabela 2), "análise dos trabalhos", foi realizada com o uso software estatístico R (versão 3.6.1.) e de seu pacote Bibliometrix (http://www.bibliometrix.org, Aria e Cuccurullo, 2017). Com a utilização desse pacote, foi possível extrair dados dos artigos mais citados, redes de colaboração entre autores, termos mais citados, dentre outras informações necessárias para a quarta etapa de visualização.

A visualização (Etapa 4, conforme Tabela 2) foi realizada em dois momentos. No primeiro momento, foram compilados os dados estatísticos, utilizando o pacote Bibliometrix e criadas as tabelas necessárias à análise segundo categorias (documentos, autores, palavras-chave, países, afiliações, referências e periódicos). Em um segundo momento, foram gerados mapas bibliométricos com esses dados no software VOSviewer, ferramenta criada por Van Eck e Waltman (2010) e que possibilita a visualização dos dados por rótulos, densidade, agrupamentos e níveis de dispersão.

o VOSviewer mede as distâncias entre os itens por meio do escalonamento multidimensional. Assim, quanto mais os itens foram citados em conjunto, mais forte é a relação entre eles e mais próximos eles aparecem entre si. 0 tamanho dos itens demonstra a quantidade de citações que eles receberam individualmente, ou seja, quanto maiores, mais citados foram os itens expostos nos mapas. A próxima seção, portanto, apresenta os resultados e análises dos levantamentos que tratam de inovação social e empreendedorismo social em conjunto. A quinta etapa (Interpretação dos resultados, conforme Tabela 2) está dividida nas seções que apresentam os resultados e a discussão dos dados, e as considerações finais.

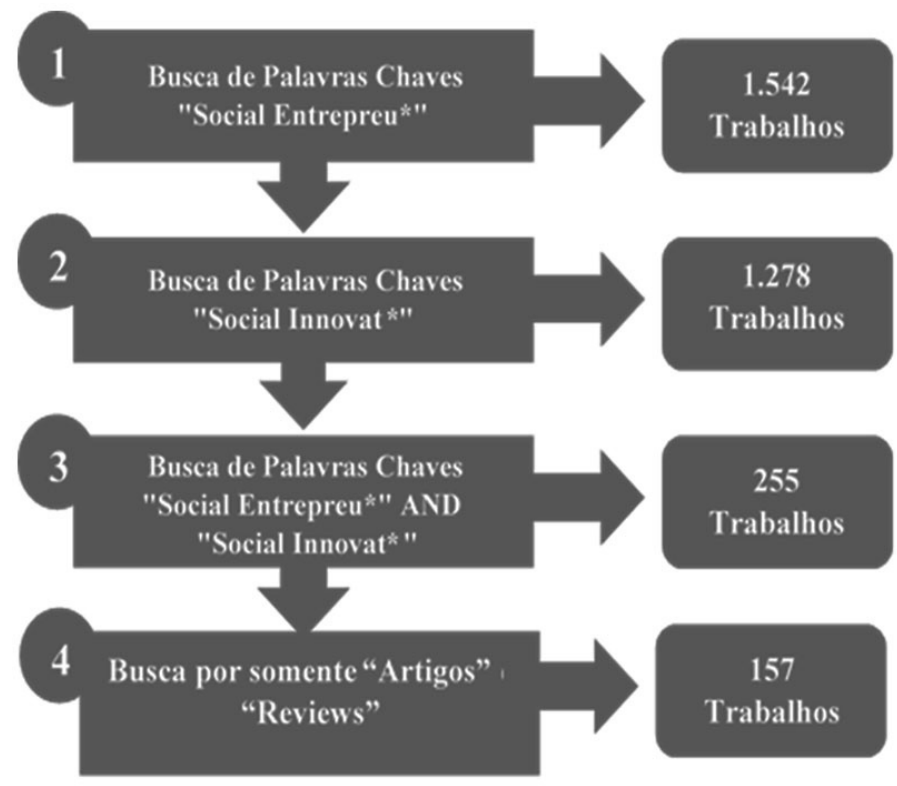

Figura 1. Fluxo das atividades Fonte: elaboração própria. Fonte: elaboraçao própria. 


\section{Resultados}

A partir dos dados coletados na plataforma Scopus, utilizando o pacote Bibliometrix, do software R para criar o gráfico (Figura 2), é possível avaliar a evolução das publicações nas áreas de empreendedorismo social e inovação social em conjunto ao longo dos anos. 0 eixo $X$ do gráfico apresenta os anos de publicação, e o eixo $Y$ a quantidade.

É possível identificar dois períodos temporais distintos em termos de quantidade de artigos e revisões publicadas, sendo o primeiro entre 1989 e 2010, com publicações esparsas sobre o tema, e o segundo, a partir de 2011, quando foram publicados 11 artigos. A figura também permite verificar uma tendência de crescimento na quantidade de artigos publicados ao longo dos anos.

A partir da análise de citações é possível avaliar a natureza histórica e dinâmica na qual os assuntos foram desenvolvidos na literatura acadêmica, além de identificar os grupos de cientistas, suas publicações, instituições e pesquisadores de maior impacto (Hjørland, 2013). Dentre os periódicos com mais artigos citados sobre empreendedorismo social e inovação social em conjunto, verificou-se o Journal of Social Entrepreneurship, especializado na área de empreendedorismo social, com 14 publicações. Além disso, 52\% (81) dos periódicos apresentaram publicação única, ou seja, apenas um artigo sobre os assuntos abordados, conforme se verifica na Tabela 3. Além da quantidade de trabalhos publicados, o Journal of Social Entrepreneurship é o periódico que apresentou o maior h-Index (7), índice que mede a produtividade e o impacto de cientistas e periódicos.

0 escopo dos periódicos que mais publicaram artigos ligados ao empreendedorismo social e inovação social resumem-se a: modelos de negócios para exploração de inovações sociais (Journal of Social Entrepreneurship); Terceiros Setor, voluntariado e organizações sem fins lucrativos (Voluntas); desenvolvimento sustentável e cooperativas (Ciriec); desenvolvimento econômico local e regional por meio do empreendedorismo e pequenas empresas (Entrepreneurship and Regional Development); e processos e resultados empreendedores de pequenos negócios (International Small Business Journal).

Quanto aos trabalhos mais citados na base Scopus (Tabela 4), destaca-se a revisão empreendida por Dacin, Dacin e Tracey (2011), que desde a sua publicação recebeu 370 citações somente em trabalhos publicados na base avaliada e lida com aspectos conceituais a respeito do empreendedorismo social. Interessante observar que entre os dez artigos mais citados a respeito de empreendedorismo social e inovação social, somente Perrini, Vurro e Constanzo (2010) e Shaw e de Bruin (2013) foram publicados em periódicos que mais publicam sobre os temas, conforme Tabela 3.

A Figura 3 apresenta os vinte autores e autoras que mais publicaram trabalhos entre 2010 e 2019 estudando os temas em análise. Nesta figura, o eixo $X$ indica 0 ano em que ocorreu cada publicação, e o eixo $Y$ traz o nome de cada um dos autores e autoras. Os círculos representam artigos publicados de modo que, quanto maior for o círculo, maior é a quantidade de publicações naquele ano. A linha que conecta cada um desses círculos, indica a constância de artigos publicados pelos autores em questão. Em outras palavras, quanto mais longa for a linha, mais consistente é a quantidade de trabalhos publicados por um mesmo autor. Assim, a Figura 3 indica tanto quantidade, quanto frequência de publicações, demonstrando a presença do autor no campo em questão.

$\mathrm{Na}$ Figura 3, verifica-se que os temas atraem pesquisadores de diversas áreas de conhecimento e que, geralmente, publicam poucos trabalhos sobre empreendedorismo social e inovação social. Isto confere um aspecto fragmentado e multidisciplinar ao campo e dificulta a retenção de pesquisadores dedicados ao crescimento e amadurecimento do campo (Landström e Harirchi, 2018). Além disso, é possível identificar autores como Tracey, Bacq, Griffiths e Kickul que possuem publicações entre 2010 e 2018, demonstrando esforços ao tratar com questões relacionadas aos fenômenos em estudo. Por outro lado, verificou-se autores com poucos trabalhos na área, o que reforça o caráter pontual e esporádico de suas pesquisas.

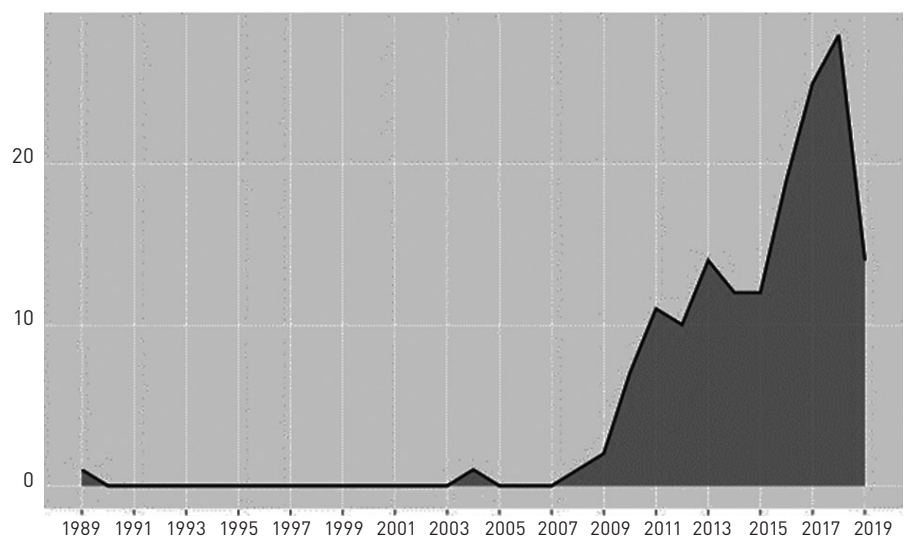

Figura 2. Produção anual de trabalhos sobre empreendedorismo social e inovação social de forma conjunta indexadas na base Scopus Fonte: elaboração própria.

Tabela 3. Periódicos com maior número de publicações sobre empreendedorismo social e inovação social de forma conjunta

\begin{tabular}{lll}
\hline Periódico & $\begin{array}{l}\text { N. de artigos } \\
\text { citados }\end{array}$ & h-index \\
\hline $\begin{array}{l}\text { Journal of Social Entrepreneurship } \\
\begin{array}{l}\text { Voluntas: International Journal of Voluntary } \\
\text { and Nonprofit Organizations }\end{array}\end{array}$ & $\begin{array}{l}14 \\
\begin{array}{l}\text { Ciriec-España Revista de Economia Publica } \\
\text { Social y Cooperativa }\end{array}\end{array}$ & 5 \\
$\begin{array}{l}\text { Entrepreneurship and Regional Development } \\
\text { International Small Business Journal }\end{array}$ & 5 & 2 \\
\hline
\end{tabular}

Fonte: elaboração própria. 
No que diz respeito às diferenças entre a produção por país e as citações que os pesquisadores de determinados países recebem, apesar de os Estados Unidos da América (EUA) apresentarem a maior produção, a análise das referências demonstra que os trabalhos do Canadá receberam mais do que o dobro de citações (Tabela 5). Uma das principais explicações está no trabalho de Dacin et al. (2011), com 372 citações na base da Scopus (Tabela 3).

Vale notar que embora um dos principais periódicos apresentados na Tabela 3 seja de origem ibérica (CiriecEspaña Revista de Economia Publica Social y Cooperativa), a Espanha consta em décimo lugar na lista de países que mais possui artigos citados. Além disso, embora os trabalhos de Moore e Westley (2011), Westley e Antadze (2010) e Biggs et al. (2010) contenham autores de instituições belgas, o país permanece pouco citado e sequer aparece entre os dez mais relevantes na lista em questão.

Enquanto a Tabela 5 apresenta o número de artigos oriundos de determinados países e quantas vezes os artigos desses países foram citados quando as publicações tratam de empreendedorismo social e inovação social, a Tabela 6 apresenta os dez artigos mais utilizados no referencial teórico. Isto é, os artigos arrolados (Tabela 6) representam a estrutura intelectual e científica dos trabalhos publicados na base Scopus que tratam dos temas em questão de forma conjunta.

Ainda com base nos trabalhos mais referenciados, dentre os 157 artigos analisados, a Figura 4 apresenta um mapa bibliométrico dos cinquenta trabalhos que mais foram citados na base de dados. De acordo com Van Eck e Waltman (2010), um mapa bibliométrico é a representação visual da rede de ligações existente, nesse caso, entre os artigos analisados. Esse mapa apresenta as redes de co-citações, que permitem compreender as publicações de maior impacto e a identificação de artigos fundamentais para a comunidade científica (Grácio, 2016). Assim, quanto maiores são os nós, mais vezes um artigo foi citado; e quanto mais espessos forem os laços que ligam esses nós, mais forte é a relação entre esses trabalhos, e mais vezes eles foram citados em conjuntos em distintas publicações.

Na Figura 4 pode-se verificar três grandes grupos. 0 primeiro deles (Grupo 1, localizado à direita na imagem) é liderado pelos trabalhos de Mair e Marti (2006), Zahra, Gedajlovic, Neubaum e Shulman (2009), e Peredo e Mclean (2006), com 49, 14 e 14 citações respectivamente.

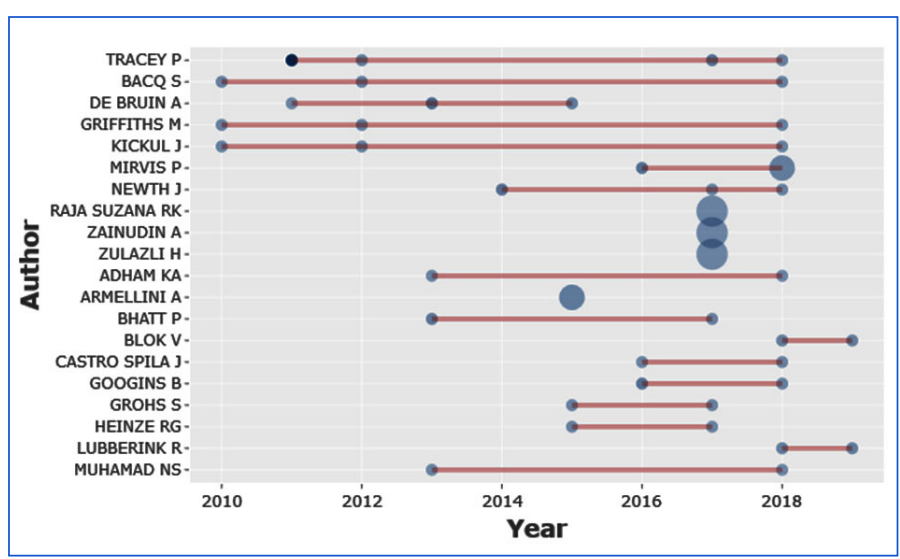

Figura 3. Produção dos autores em empreendedorismo social e inovação social de forma conjunta ao longo dos anos

Fonte: elaboração própria.

Tabela 4. Dez artigos mais citados na base de dados Scopus

\begin{tabular}{|c|c|c|c|c|c|}
\hline Autor & Título & Periódico & Ano & $\begin{array}{l}\text { Citações } \\
\text { (total) }\end{array}$ & $\begin{array}{l}\text { Citações } \\
\text { (Ano) }\end{array}$ \\
\hline $\begin{array}{l}\text { Dacin, Dacin, } \\
\text { Tracey }\end{array}$ & Social entrepreneurship: A critique and future directions & Organization science, 22(5) & 2011 & 372 & 46,5 \\
\hline Moore, Westley & $\begin{array}{l}\text { Surmountable chasms: networks and social innovation for } \\
\text { resilient systems }\end{array}$ & Ecology and society, 16(1) & 2011 & 151 & 18,9 \\
\hline Westley, Antadze & $\begin{array}{l}\text { Making a difference: Strategies for scaling social innovation } \\
\text { for greater impact }\end{array}$ & Innovation Journal, 15(2) & 2010 & 133 & 14,8 \\
\hline $\begin{array}{l}\text { Biggs, Westley, } \\
\text { Carpenter }\end{array}$ & $\begin{array}{l}\text { Navigating the back loop: fostering social innovation and } \\
\text { transformation in ecosystem management }\end{array}$ & Ecology and society, 15(2) & 2010 & 121 & 13,4 \\
\hline Dawson, Daniel & Understanding social innovation: a provisional framework. & $\begin{array}{l}\text { Journal of Technology } \\
\text { Management, } 51(1)\end{array}$ & 2010 & 92 & 10,2 \\
\hline $\begin{array}{l}\text { van der Have, } \\
\text { Rubalcaba }\end{array}$ & $\begin{array}{l}\text { Social innovation research: An emerging area of innovation } \\
\text { studies? }\end{array}$ & Research Policy, 45(9) & 2016 & 82 & 27,3 \\
\hline Novkovic & Defining the co-operative difference & $\begin{array}{l}\text { The Journal of Socio-Economics, } \\
37(6)\end{array}$ & 2008 & 81 & 7,4 \\
\hline $\begin{array}{l}\text { Perrini, Vurro, } \\
\text { Constanzo }\end{array}$ & $\begin{array}{l}\text { A process-based view of social entrepreneurship: From } \\
\text { opportunity identification to scaling-up social change in the } \\
\text { case of San Patrignano }\end{array}$ & $\begin{array}{l}\text { Entrepreneurship and regional } \\
\text { development, 22(6) }\end{array}$ & 2010 & 79 & 8,8 \\
\hline Dess & $\begin{array}{l}\text { A tale of two cultures: Charity, problem solving, and the } \\
\text { future of social entrepreneurship }\end{array}$ & Journal of business ethics, $111(3)$ & 2012 & 64 & 9,1 \\
\hline Shaw, de Bruin & $\begin{array}{l}\text { Reconsidering capitalism: the promise of social innovation } \\
\text { and social entrepreneurship? }\end{array}$ & $\begin{array}{l}\text { International Small Business } \\
\text { Journal, 31(7) }\end{array}$ & 2013 & 57 & 9,5 \\
\hline
\end{tabular}

Fonte: elaboração própria. 
Pela leitura dos resumos desses artigos é possível identificar que o conjunto de trabalhos conectados neste cluster está relacionado à literatura teórica dedicada à compreensão e definição o empreendedorismo social como campo teórico por meio de discussões críticas e da elaboração de tipologias.

Já o Grupo 2 llocalizado na região superior da Figura 4) contém referências associadas ao tema do empreendedorismo social de uma forma conceitual. Destacam-se os trabalhos de Nicholls (2010) e Haugh (2007), com 13 citações cada. Também se caracteriza como um agrupamento sem grande concentração de autores e traz aspectos do empreendedorismo social ou da inovação social relacionados ao desenvolvimento e inclusão econômica de diversas comunidades.

Tabela 5. Produção científica e número de citações por país

\begin{tabular}{llll}
\hline \multirow{2}{*}{ País } & $\begin{array}{c}\text { Produção por país } \\
\text { Quantidade }\end{array}$ & País & Artigos citados por país \\
Quantidade
\end{tabular}

Fonte: elaboração própria.

O Grupo 3 (localizado à esquerda na Figura 4) apresenta menor concentração em relação ao primeiro, o que pode ser verificado nos trabalhos de Phills et al. (2008), Defourny e Nyssens (2010), e Shaw e Carter (2007), com 12,10 e 10 citações, respectivamente. Amparado nos três principais artigos deste cluster é possível inferir que a abordagem trabalhada neles diz respeito ao papel da inovação social nos processos e resultados encontrados no empreendedorismo social.

Em relação à análise textual (Zupic e Čater, 2015), isto é, a associação das palavras-chave utilizadas para a busca dos artigos indexados na plataforma Scopus (Figura 4), verifica-se que, conforme esperado, as principais palavras são "social innovation" e "social enterpreneurship" apresentadas como os nós centrais destacados.

A análise de texto do bibliométrico (Figura 5) apresenta três clusters principais. Em relação ao primeiro cluster (Grupo 1), mais relacionado às inovações sociais, é possível verificar palavras como measurement, business model, scale, intrapreneurship, social networks e corporate social responsibility. O segundo cluster de maior densidade (Grupo 2, no canto inferior esquerdo) está relacionado às duas principais palavras Isocial entrepreneurship e social innovationl e traz aspectos relacionados a políticas públicas, políticas sociais, caridade, e inclusão por meio desse tipo de negócios. 0 terceiro cluster (Grupo 3, majoritariamente no lado direito da figura), mais esparso, está relacionado a empresas sociais e tem como termos relacionados empregabilidade, serviços transformativos, e sociedade civil.

Interessante notar que o segundo e terceiro clusters trazem nomes de países ou regiões em desenvolvimento, caso da Índia, Brasil, Hong Kong e Malásia. Isso indica que embora os países que mais produzem trabalhos na área de empreendedorismo social e inovação social sejam países desenvolvidos le.g. Estados Unidos, Reino Unido e Espanha), é possível que o objeto de estudo seja países em desenvolvimento. Uma explicação para isso está no potencial transformador das práticas de empreendedorismo social e inovação social em nações que necessitam enfrentar problemas sociais (Gaiotto, 2016; OECD/ Eurostat, 2018).

\subsection{Discussão dos resultados}

Compreender os limites, a extensão e as relações entre o empreendedorismo social e a inovação se torna cada vez mais importante para que essas áreas evoluam como campo de pesquisa e sejam aprimoradas como práticas sociais (Lortie e Cox, 2018). Embora tenha-se verificado que ambas as áreas são relativamente novas como campos de pesquisa (Farinha et al., 2020; González e Lutsak-Yaroslava, 2017; Van der Have e Rubalcaba, 2016), elas encontram-se em processo acelerado de crescimento e expansão para se desenvolver em um campo consolidado de estudo. Esta pesquisa também verificou o aumento do número de publicações de artigos científicos dentre os anos de 2009 a 2019, com ênfase entre os anos de 2016 a 2019, o que se assemelha ao defendido por Farinha et al. (2020).

Além disso, corroborando com o estudo de ReyMartí et al. (2016), que realizou uma investigação bibliométrica no campo do empreendedorismo social, o desenvolvimento de pesquisas sobre as áreas de inovação social e empreendedorismo social estão concentradas em países como Reino Unido e Estados Unidos, e divulgados na língua inglesa. 0 que demonstra que há espaço para esse tipo de pesquisa em outras regiões tais como os países latino-americanos (BlancoAriza et al., 2019).

Contudo,é possível perceberqueasregiões de interesse desses pesquisadores estão concentradas em países em desenvolvimento, caso de Índia, Brasil, e Malásia, por exemplo. Explica-se esse fenômeno pelo fato de tanto empreendedorismo social como inovação social, buscarem criar valor social e solução para problemas sociais, como a pobreza e a fome (Nicholls et al., 2015).

As análises contidas neste trabalho buscaram apresentar um guia para pesquisadores que possuam interesse em estudos que relacionam os campos do empreendedorismo social e da inovação social. Foram oferecidas informações sobre os principais autores, artigos científicos utilizados e citados por autores da área, e a relação entre os campos de estudo, e demonstrados quais periódicos e autores possuem destaque nesta temática. Diante disso, destacam-se, a seguir, algumas possíveis perguntas de pesquisa para direcionar estudos futuros na área. 
- Como se configura a produção científica em empreendedorismo social e inovação social oriunda de países em desenvolvimento?

- Dado que o empreendedorismo social e a inovação social são fenômenos que visam a solução de problemas sociais e a criação de valor social, é possível identificar algum tipo de contribuição de fato nas redes sociais estabelecidas para a produção de pesquisas científicas? Isto é, há colaborações e intercâmbios entre instituições, centros de pesquisa, e autores entre países desenvolvidos e países em desenvolvimento?

\section{Considerações finais}

"Empreendedorismo social" e "inovação social" podem ser vistos como processos ou resultados que buscam, de forma geral, melhorar o bem-estar de indivíduos e sociedades por meio de iniciativas que prezam pela inclusão social e valorização de pessoas e atividades que, de certa maneira, foram negligenciadas pelo mercado ou pelo Estado (Gaiotto, 2016; Mulganet al., 2013; OECD/Eurostat, 2018).

Tabela 6. Base conceitual teórica dos artigos que tratam de empreendedorismo social e inovação social em conjunto na base Scopus

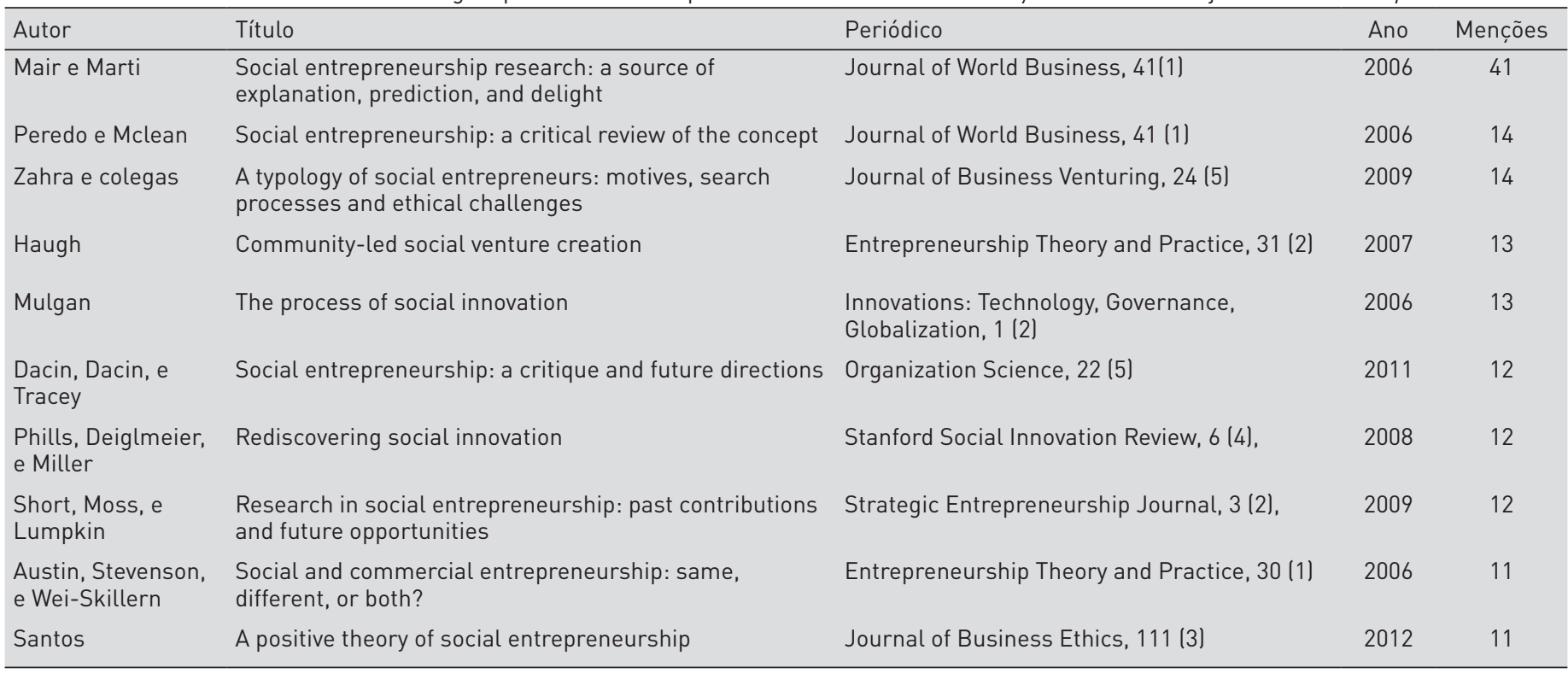

Fonte: elaboraçao própria.

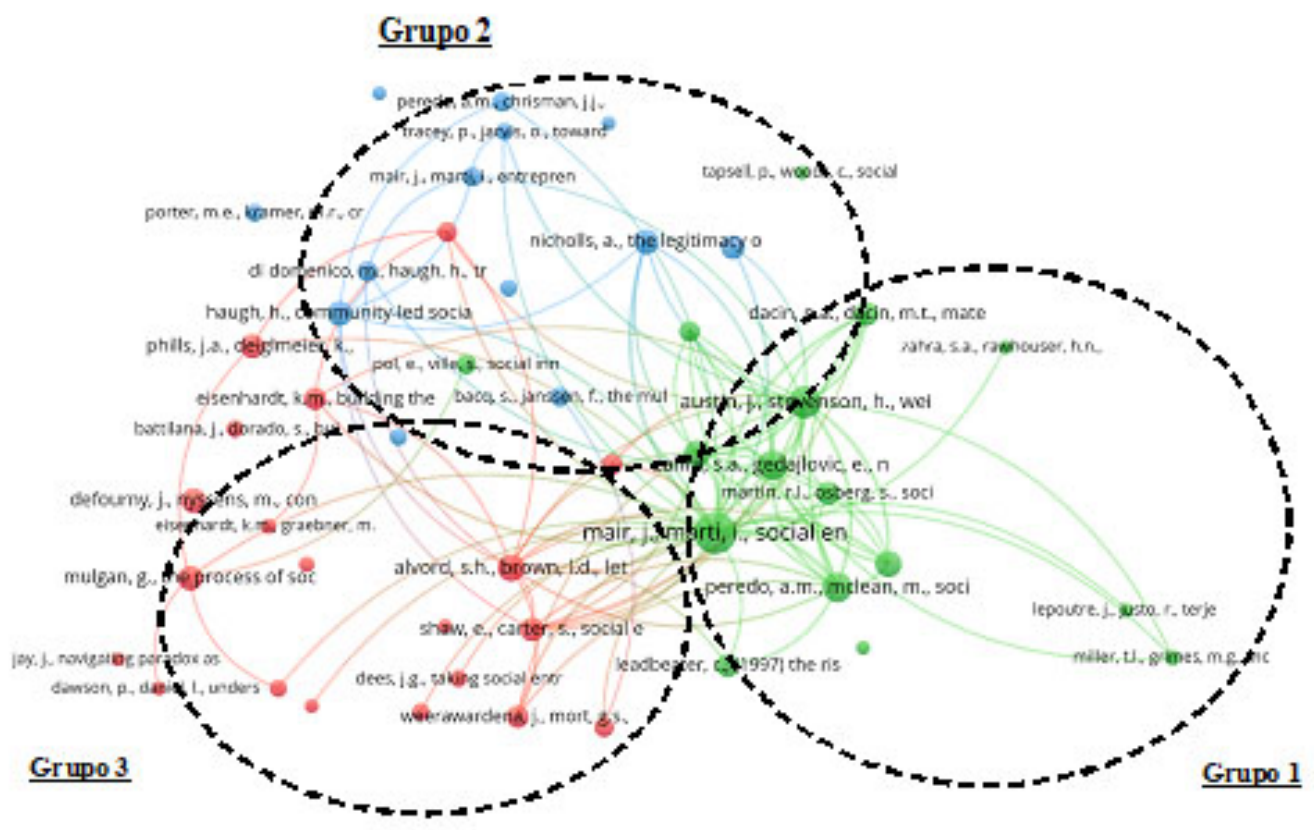

Figura 4. Cinquenta trabalhos mais referenciados em publicações sobre empreendedorismo social e inovação social em conjunto na base Scopus Fonte: elaboração própria. 


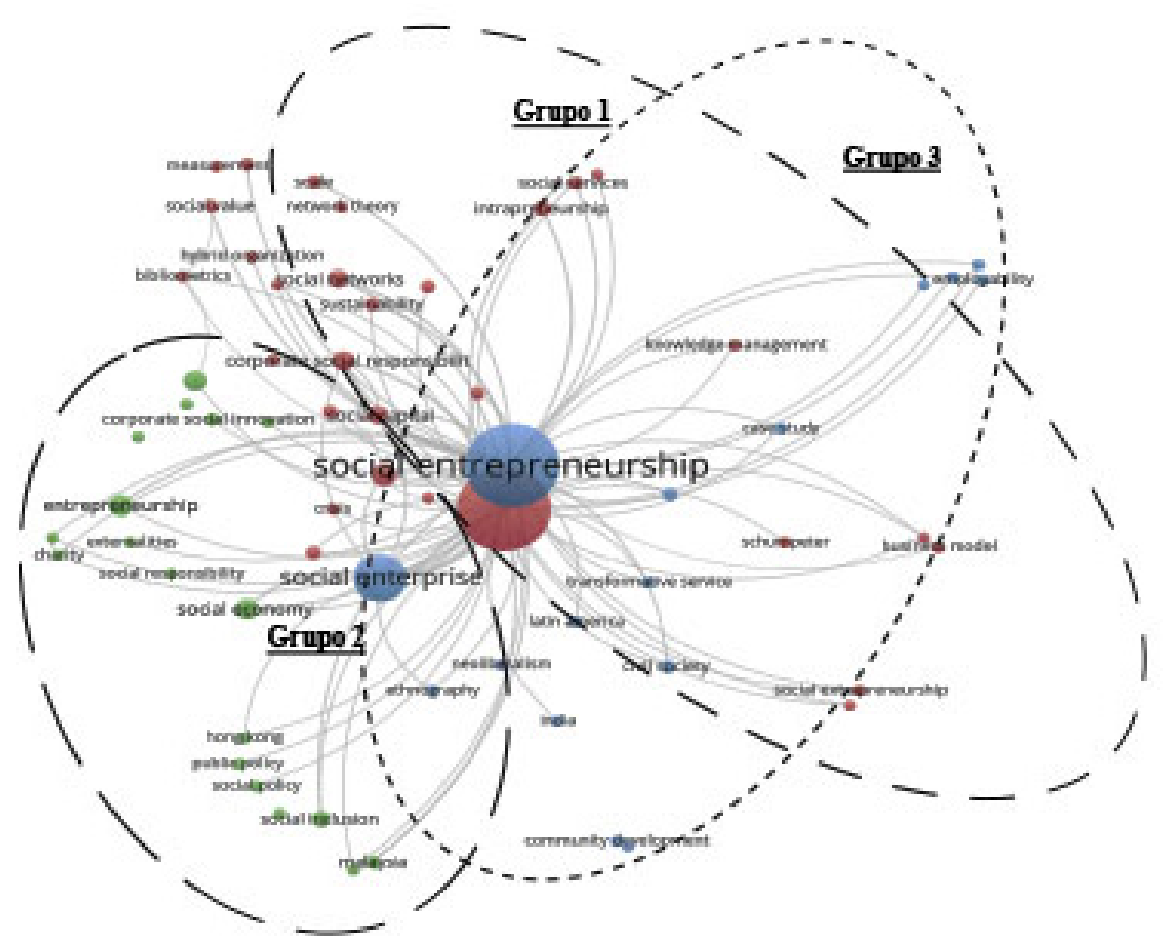

Figura 5. Palavras-chave utilizadas pelos autores.

Fonte: elaboração própria.

Notando-se a relevância da atuação prática dessas temáticas, bem como o interesse renovado por parte dos pesquisadores pelos conceitos de inovação social e empreendedorismo social (Cunha, Benneworth e Oliveira, 2017), constatou-se a existência de lacunas significativas quando investigadas conjuntamente. Tanto é que Phillips et al. (2015) destacam a necessidade de estudos que contemplem conjuntamente o empreendedorismo social e a inovação social, no intento de desenvolver uma compreensão compartilhada da relação conceitual entre eles.

Por meio da análise bibliométrica dos trabalhos que abordam de maneira conjunta o empreendedorismo social e a inovação social, destaca-se que eles começaram a ser publicados em 1989 com o seminal artigo de Ganne (1989), que trata de empreendedorismo social, inovações sociais e as redes na região sudeste da França. É possível verificar que há um interesse crescente, especialmente a partir de 2011, quando as publicações ultrapassam a quantia de dez artigos anuais.

Vale destacar que foram identificadas com maior ênfase, a existência de estudos relacionados à países e regiões em desenvolvimento, isto é, o empreendedorismo social e a inovação social como duas frentes que podem ser trabalhadas em conjunto, em prol de uma sociedade mais sustentável em termos econômicos, sociais e ambientais. No que diz respeito aos principais trabalhos identificados nesta pesquisa, observou-se que elas apresentaram como tema principal o empreendedorismo social e que a inovação social aparece como aspecto secundário, característica ou resultado do processo empreendedor.
Dentre as limitações deste estudo se encontram a utilização de apenas uma base de dados para a pesquisa (Scopus), além da seleção das palavras-chave aplicadas, considerando a existência de outros possíveis diversos agrupamentos de palavras-chaves que poderiam ser combinados.

Por outro lado, o objetivo não foi realizar uma análise da qualidade do conteúdo dos artigos selecionados, deixando a possibilidade da realização de revisões sistemáticas para estudos futuros. Recomenda-se também para futuras pesquisas a utilização de outras bases indexadoras de trabalhos, caso da Web of Science ou Google Scholar, aprofundando de maneira qualitativa os estudos identificados.

\section{Conflito de interesses}

Os autores declaram não haver conflito de interesses.

\section{Referências}

Adams, D., \& Hess, M. (2010). Social innovation and why it has policy significance.The Economic and Labour Relations Review, 21(2), 139155. https://doi.org/10.1177/103530461002100209

Aria, M., \& Cuccurullo, C. (2017). Bibliometrix: An R-tool for comprehensive science mapping analysis. Journal of Informetrics, 11(4), 959-975. https://doi.org/10.1016/j.joi.2017.08.007

Ayob, N., Teasdale, S., \& Fagan, K. (2016). How social innovation "Came to Be": Tracing the evolution of a contested concept. Journal of Social Policy, 45(4), 635-653. https://doi.org/10.1017/S004727941600009X

Biggs, R., Westley, F. R., \& Carpenter, S. R. (2010). Navigating the back loop: fostering social innovation and transformation in ecosystem management. Ecology and society, 15(2), 9. https://doi.org/10.5751/ES-03411-150209 
Blanco-Ariza, A. B., Messino-Soza, A., Vázquez-García, A. W., \& Melamed-Varela, E. (2019). Social innovation in the non-profit organization framework: A review. Social Sciences, 8(8). https://doi.org/10.3390/socsci8080236

Carmona, V. C., Martens, D. P., Leão, A. L. D. B. C., Nassif, V. M. J., \& Freitas, H. M. R. (2018). Social entrepreneurship: a bibliometric approach in the administration and business field. Estudios Gerenciales, 34(149), 399-410.

https://doi.org/10.18046/j.estger.2018.149.2912

Chalmers, D. (2013). Social innovation: An exploration of the barriers faced by innovating organizations in the social economy. Local Economy, 28(1), 17-34. https://doi.org/10.1177/0269094212463677

Cohen, B., \& Winn, M. I. (2007). Market imperfections, opportunity and sustainable entrepreneurship. Journal of business venturing, 22(1), 29-49. https://doi.org/10.1016/j.jbusvent.2004.12.001

Cunha, J., Benneworth, P., \& Oliveira, P. (2017). Social Entrepreneurship and Social Innovation: A Conceptual Distinction. In Management Association, I. (Ed.), Entrepreneurship: Concepts, Methodologies, Tools, and Applications (pp. 1619-1643). Pensilvania: IGI Global. http://doi:10.4018/978-1-5225-1923-2.ch069

Dacin, M. T., Dacin, P. A., \& Tracey, P. (2011). Social entrepreneurship: A critique and future directions. Organization science, 22(5), 1203-1213. https://doi.org/10.1287/orsc.1100.0620

Dacin, P. A., Dacin, M. T., \& Matear, M. (2010). Social entrepreneurship: Why we don't need a new theory and how we move forward from here. Academy of management perspectives, 24(3), 37-57. https://doi.org/10.5465/amp.24.3.37

Dawson, P., \& Daniel, L. (2010). Understanding social innovation: a provisional framework. International Journal of Technology Management, 51(1), 9-21. https://doi.org/10.1504/IJTM.2010.033125

Defourny, J., \& Nyssens, M. (2010). Conceptions of social enterprise and social entrepreneurship in Europe and the United States: Convergencesand divergences. Journalofsocialentrepreneurship, 1(1), 32-53. https://doi.org/10.1080/19420670903442053

Dionisio, M. (2019). The evolution of social entrepreneurship research: a bibliometric analysis. Social Enterprise Journal, 15(1), 22-45. https://doi.org/10.1108/SEJ-05-2018-0042

Durán-Sánchez, A., Peris-Ortiz, M., Álvarez-García, J., \& del Río, M.D.L.C. (2018). Entrepreneurship and Social Innovation for Sustainability. Bibliometric Analysis. In Strategies and Best Practices in Social Innovation (pp. 11-29). Cham: Springer.

Farfus, D., \& Rocha, M. D. S. (2007). Inovação Social: um conceito em construção. In Daniele Farfus e Maria Cristhina de Souza Rocha, Inovações Sociais (pp.13-34). Curitiva: SESI/SENAI/IEL/UNINDUS.

Farinha, L., Sebastião, J. R., Sampaio, C., \& Lopes, J. (2020). Social innovation and social entrepreneurship: discovering origins, exploring current and future trends. International Review on Public and Nonprofit Marketing, 17(1), 77-96. https://doi.org/10.1007/s12208-020-00243-6

Foroudi, P., Akarsu, T. N., Marvi, R., \& Balakrishnan, J. (2020). Intellectual evolution of social innovation: A bibliometric analysis and avenues for future research trends. Industrial Marketing Management, In press, 1-21. https://doi.org/10.1016/j.indmarman.2020.03.026

Gaitán-Angulo, M., Díaz, J. C., Viloria, A., Lis-Gutiérrez, J. P., \& Rodríguez-Garnica, P. A. (2018). Bibliometric analysis of social innovation and complexity (Databases Scopus and Dialnet 20072017). In International Conference on Data Mining and Big Data (pp. $23-$ 30). Cham: Springer.

Gaiotto, S. A. V. (2016). Empreendedorismo Social: um estudo bibliométrico sobre a produção nacional e internacional. REGEPE-Revista de Empreendedorismo e Gestão de Pequenas Empresas, 5(2), 101-123. https://doi.org/10.14211/regepe.v5i2.358

Ganne, B. (1989). Regional dynamics of innovation: A look at the Rhône Alpes Region. Entrepreneurship \& Regional Development, 1(2), 147154. https://doi.org/10.1080/08985628900000013

Grácio, M. C. C. (2016). A coplamento bibliográfico e análise de cocitação: revisão teórico-conceitual. Encontros Bibli: revista eletrônica de biblioteconomia e ciência da informação, 21(47), 82-99. https://doi.org/10.5007/1518-2924.2016v21n47p82

González, M. D. C. P., \& Lutsak-Yaroslava, N. V. (2017). La producción científica sobre la innovación social para el desarrollo local. Una revisión bibliométrica. Revista Prisma Social, (19), 146-182.
Gutiérrez-Salcedo, M., Martínez, M. Á., Moral-Munoz, J. A., HerreraViedma, E., \& Cobo, M. J. (2018). Some bibliometric procedures for analyzing and evaluating research fields. Applied Intelligence, 48(5), 1275-1287. https://doi.org/10.1007/s10489-017-1105-y

Hall, J. K., Daneke, G. A., \& Lenox, M. J. (2010). Sustainable development and entrepreneurship: Past contributions and future directions. Journal of Business Venturing, 25(5), 439-448. https://doi.org/10.1016/j.jbusvent.2010.01.002

Haugh, H. (2007). Community-led social venture creation. Entrepreneurship theory and practice, 31(2), 161-182. https://doi.org/10.1111/j.1540-6520.2007.00168.x

Hjørland, B. (2013). Citation analysis: A social and dynamic approach to knowledge organization. Information Processing \& Management, 49(6), 1313-1325.

Hota, P. K., Subramanian, B., \& Narayanamurthy, G. (2019). Mapping the Intellectual Structure of Social Entrepreneurship Research: A Citation/Co-citation Analysis. Journal of Business Ethics, 166, 89-114. https://doi.org/10.1007/s10551-019-04129-4

Johnson, C., \& Gilles, R. P. (2003). Spatial social networks. In Networks and groups (pp. 51-77). Springer, Berlin, Heidelberg.

Kraus, S., Filser, M., O'Dwyer, M., \& Shaw, E. (2014). Social Entrepreneurship: An exploratory citation analysis. Review of Managerial Science, 8(2), 275-292. https://doi.org/10.1007/s11846-013-0104-6

Landström, H. \& Harirchi, G. (2018). The social structure of entrepreneurship as a scientific field. Research Policy, 47, 650-662. https://doi.org/10.1016/j.respol.2018.01.013

Landström, H., Harirchi, G., \& Åström, F. (2012). Entrepreneurship: Exploring the knowledge base. Research Policy, 41(7), 1154-1181.

Lortie, J., \& Cox, K. C. (2018). On the boundaries of social entrepreneurship: A review of relationships with related research domains. International Entrepreneurship and Management Journal, 14(3), 639-648.

Macke, J., Sarate, J. A. R., Domeneghini, J., \& da Silva, K. A. (2018). Where do we go from now? Research framework for social entrepreneurship. Journal of Cleaner Production, 183, 677-685. https://doi.org/10.1016/j.jclepro.2018.02.017

Mair, J., \& Marti, I. (2006). Social entrepreneurship research: A source of explanation, prediction, and delight. Journal of world business, 41(1), 36-44. https://doi.org/10.1016/j.jwb.2005.09.002

Meho, L. I., \& Yang, K. (2006). A new era in citation and bibliometric analyses: Web of Science, Scopus, and Google Scholar. arXiv preprint cs/0612132.

Moore, M. L., \& Westley, F. (2011). Surmountable chasms: networks and social innovation for resilient systems. Ecology and society, 16(1), 5.

Moroz, P. W., \& Hindle, K. (2012). Entrepreneurship as a process: Toward harmonizing multiple perspectives. Entrepreneurship Theory and Practice, 36(4), 781-818. https://doi.org/10.1111/j.1540-6520.2011.00452.x

Moulaert, F. (2016). Social innovation: Institutionally embedded, territorially (re) produced. In Diana MacCallum \& Serena Vicari Haddock, Social innovation and territorial development ( $1^{\text {st }}$ ed) (pp. 2740). London: Routledge.

Mulgan, G. (2006). The process of social innovation. Innovations: technology, governance, globalization, 1(2), 145-162. https://doi.org/10.1162/itgg.2006.1.2.145

Mulgan, G., Joseph, K., \& Norman, W. (2013). Indicators for social innovation. In Fred Gault (ed.), Handbook of Innovation Indicators and Measurement (pp. 420-438). Cheltenham: Edward Elgar Publishing.

Mulyaningsih, H. D., Yudoko, G., \& Rudito, B. (2016). Knowledgebased social innovation process in social enterprise: A conceptual framework. Advanced Science Letters, 22(5-6), 1393-1397. https://doi.org/10.1166/asl.2016.6621

Murray, R., Caulier-Grice, J. \& Mulgan, G. (2010). The Open Book of Social Innovation. London: The Young Foundation.

Nicholls, A. (2010). The legitimacy of social entrepreneurship: Reflexive isomorphism in a pre-paradigmatic field. Entrepreneurship theory and practice, 34(4), 611-633. https://doi.org/10.1111/j.1540-6520.2010.00397.x

Nicholls, A., Simon, J., Gabriel, M., \& Whelan, C. (Eds.). (2015). New frontiers in social innovation research. London: Palgrave Macmillan. 
OECD/Eurostat. (2018). Oslo Manual: The Measurement of Scientific, Technological and Innovation Activities. Guidelines for Collecting, Reporting and Using Data on Innovation.

Onozato, É., \& Teixeira, R. M. (2010). Processo de criação de organizações com fins sociais: estudo de casos múltiplos em CuritibaParaná. Revista Contabilidade, Gestão e Governança, 13(3), 38-52.

Osareh, F. (1996). Bibliometrics, citation analysis and co-citation analysis: A review of literature I. Libri, 46(3), 149-158. https://doi.org/10.1515/libr.1996.46.3.149

Peredo, A. M., \& McLean, M. (2006). Social entrepreneurship: A critical review of the concept. Journal of world business, 41(1), 56-65.

Perrini, F., Vurro, C., \& Costanzo, L. A. (2010). A process-based view of social entrepreneurship: From opportunity identification to scalingup social change in the case of San Patrignano. Entrepreneurship and regional development, 22(6), 515-534. https://doi.org/10.1080/08985626.2010.488402

Phillips, W., Lee, H., Ghobadian, A., O'Regan, N., \& James, P. (2015). Social innovation and social entrepreneurship: A systematic review. Group \& Organization Management, 40(3), 428-461. https://doi.org/10.1177/1059601114560063

Phills, J. A., Deiglmeier, K., \& Miller, D. T. (2008). Rediscovering social innovation. Stanford Social Innovation Review, 6(4), 34-43.

Rey-Martí, A., Ribeiro-Soriano, D., \& Palacios-Marqués, D. (2016). A bibliometric analysis of social entrepreneurship. Journal of Business Research, 69(5), 1651-1655. https://doi.org/10.1016/j.jbusres.2015.10.033

Sassmannshausen, S. P., \& Volkmann, C. (2013). A bibliometric based review on social entrepreneurship and its establishment as a field of research (No. 2013-003). Schumpeter Discussion Papers.
Shane, S., \& Venkataraman, S. (2000). The promise of entrepreneurship as a field of research. Academy of management review, 25(1), 217-226.

Shaw, E., \& Carter, S. (2007). Social entrepreneurship. Journal of small business and enterprise development,14(3), 418-434. https://doi.org/10.1108/14626000710773529

Silveira, F. F., \& Zilber, S. N. (2017). Is social innovation about innovation? A bibliometric study identifying the main authors, citations and cocitations over 20 years. International Journal of Entrepreneurship and Innovation Management, 21(6), 459-484.

Van der Have, R. P., \& Rubalcaba, L. (2016). Social innovation research: An emerging area of innovation studies? Research Policy, 45(9), 19231935. https://doi.org/10.1016/j.respol.2016.06.010

Van Eck, N., \& Waltman, L. (2010). Software survey: VoSviewer, a computer program for bibliometric mapping. Scientometrics, 84(2) 523-538. https://doi.org/10.1007/s11192-009-0146-3

Weerawardena, J., \& Sullivan Mort, G. (2006). Investigating social entrepreneurship: A multidimensional model. Journal of World Business, 41(1), 21-35. https://doi.org/10.1016/j.jwb.2005.09.001

Westley, F., \& Antadze, N. (2010). Making a difference: Strategies for scaling social innovation for greater impact. The innovation journal: the public sector innovation journal, 15(2), 1-19.

Zahra, S. A., Gedajlovic, E., Neubaum, D. O., \& Shulman, J. M. (2009). A typology of social entrepreneurs: Motives, search processes and ethical challenges. Journal of business venturing, 24(5), 519-532.

Zupic, I., \& Čater, T. (2015). Bibliometric methods in management and organization. Organizational Research Methods, 18(3), 429-472. https://doi.org/10.1177/1094428114562629 